\title{
The urban development boundary as a planning tool for sustainable urban form
}

\author{
E. J. Cilliers \& C. B. Schoeman \\ North West University, Potchefstroom Campus, South Africa
}

\begin{abstract}
The urban core is the heart of all spatial development. However, the urban core areas in South Africa are unsustainable living places. The need for equal development, accessibility and efficiency has never been this great, especially in the Gauteng city region. The current unsustainable urban phenomenon needs to be redesigned into a compact urban core. This study evaluates the urban development boundary as a planning tool for sustainable urban form. This implies a parallel action: development inside the urban edge, and development outside the urban edge, to guide development and sustainable urban form. The urban development boundary will influence development as it guides the relation between urban and rural areas. The aim of this study was thus to determine and develop a sustainable urban form for the Gauteng city region by means of the urban development boundary concept that would lead towards a qualitative and sustainable urban environment.
\end{abstract}

Keywords: urban development boundary, sustainable development, spatial planning, sustainable urban form, Gauteng city region.

\section{Introduction}

Current urban settlement formation in the urban areas of South Africa tends to be very poor in terms of quality, service provision and standards, and thus have very little chance of developing into vibrant, enriching and efficient urban environments. While the reasons for poor environmental quality are undoubtedly diverse and complex, having political, economical and social dimensions, it is agued that the prevailing approach to layout planning in South Africa is part of the problem. 


\section{Methodology}

The Gauteng city region is in need of creative spatial development patterns and frameworks to support planning and development, and policies to guide implementation and address the current unsustainable development, ineffective planning, and fragmented urban form. The findings of the research was captured and interpreted into a logical framework allowing co-ordinated decision making. Methodology included a detailed research of the existing knowledge and status quo, compiling relevant data and information from the local and international perspectives, conducting surveys, as well as structured and semi-structured interviews, conducting a gap analysis, evaluating results, and comparing scenarios from the situation analysis in order to determine a way forward.

The literature study focused on globally accepted spatial development and planning theories, policies, frameworks and guiding legislation. The complexity of the sustainable development concept was evaluated in terms of international issues and best practices, done from an environmental management and spatial planning approach. International case studies focused on Europe, the United Kingdom and American perspectives. The national approach was guided by the National Spatial Development Perspective (2006), the Development Facilitation Act, Spatial Development Frameworks and relevant policies, as well as the Gauteng Spatial Development Perspective (2007), guiding specific provincial development. The approach was qualitative focussed.

\section{South African spatial planning and development approaches}

The major social and environmental consequences that stem from the structure and form of South African cities suggest that the current pattern of urban development is entirely unsustainable, and that urban compaction is an essential condition for improved urban performance. (Dewar [1]). Integrated development planning had emerged as a distinct approach to planning, and the objectives of integrated planning were entrenched in the core policy and legal documents including the Growth, Employment and Redistribution Programme of '94, the Constitution of '96, White Paper on Local Government '98, Green Paper on Development Planning '99, Development Facilitation Act '95, Local Government Transition Act '96, Municipal Structures Act'99 (Schoeman [2]).

Environmental legislation in South Africa also reflected the main concerns of the environmental movement (Steyn [3]). The Environment Conservation Act of 1989 made provision to determine environmental policy to guide decision-making and to prepare environmental impact reports. The introduction of the concept of environmental management was an approach to integrate environmental considerations across all stages of the spatial planning, policies, programmes, plans and projects (Sowman and Gawith [4]). However, the integration of environmental management and spatial 
planning still remains a core issues and objective in terms of researching sustainable development goals.

\section{The urban edge phenomenon}

The urban edge, functioning within the South African planning and development environment, found its origin in terms of the Subdivision of Agricultural Land Act, (Act 70 of 1970 [5]) and article 20 of the Town Planning Ordinance (RSA [6]). These two approaches both regulated development, but created confusion in terms of applicability and implementation. The Town Planning Ordinance was used in urban areas, and the Subdivision of Agricultural Land Act was used in rural areas. Therefore the urban edge was created to establish the exact point between urban and rural areas and to establish limits beyond which urban development should, as a rule, not occur in order to promote urban and environmental efficiency (Western Cape [7]). The urban edge is no rigid legislative imperative, rather a policy to achieve the principles of integration and compaction and determine future development directions (Ekurhuleni [8]).

The objective of the urban edge is to contain urban sprawl, through managing growth and densification. Specific objectives includes the defining an ideal future urban development perimeter, protect the natural resources, creating an unique character, better manage land usage and creating a model for future development. However, its stringent application, owing largely to its delineation as a cadastral line, and conflict of alignment at local and provincial level, led to its demise as a likely tool to contain growth (Gauteng [9]). The urban edge were intended to be pro-active growth management tool to contain, control, or direct growth in order to promote more compact, contiguous urban development (Western Cape [7]). This is not reflected in the current South African reality.

\section{Introduction of the urban development boundary concept}

To address the ineffectiveness of the urban edge concept, the urban development boundary is introduced as a planning tool. The urban development boundary, in context of this study, was conceptualized containing two elements: The 'urban development area' illustrating the current reality in terms of the areas where urban development may occur presently and the 'future expansion area' illustrating the future development direction (Metro Dade [10]). The urban development boundary can thus be seen as a conservation tool, a restructuring tool, an efficiency tool and a growth management tool. The core focus of the urban development boundary is thus to create a sustainable urban form by managing the urban nodes, and accommodating the impacts and pressures.

\section{Case study: urban development boundary in Gauteng}

The Spatial Development Framework of 2000 introduced the urban edge concept in Gauteng (Gauteng Department of Economic Development [11]). Following from these directives, a specific process was undertaken during the first half of 
Table 1: $\quad$ Arguments in terms of the urban development boundary.

\begin{tabular}{|c|c|}
\hline In fa & edge \\
\hline $\begin{array}{l}\text { Positive objectives, facilitates } \\
\text { restructuring and urban compaction. } \\
\text { Concept applied in accordance with } \\
\text { policy, Conservation Plan, Open Space } \\
\text { Plan and Agricultural Potential } \\
\text { Assessment. Municipalities favour the } \\
\text { concept, want local management. }\end{array}$ & $\begin{array}{l}\text { Implementation is problematic. Lack of } \\
\text { clearly defined roles at provincial level. } \\
\text { Applications considered based on } \\
\text { location and not on merit. Little } \\
\text { consideration given to growth } \\
\text { management. Over-emphasis is placed } \\
\text { on environmental aspects. }\end{array}$ \\
\hline
\end{tabular}

2001 to delineate an urban edge for Gauteng at cadastral level. This resulted in various arguments in favour of, and against the concept of the urban edge.

Although the urban edge concept has various positive objectives to offer, it was proven to be insufficient and unsustainable in the South African context, due to various constrains and difficulties regarding the implementation thereof. The proposed solution was to introduce the urban development boundary concept to the local urban environment of Gauteng, as this concept was proven to be more successful, according to international best practice. The urban development boundary has one primary advantage: development applications will be considered based on merit. If the urban development boundary is implemented universally and consistently, by all provincial departments and municipalities, it can provide appropriate capacity for future growth, enhance the alignment with existing physical features, allow appropriate non-urban development outside the boundary in accordance with specific policy requirements, and focus on more qualitative measures and growth management mechanisms.

\section{Empirical investigation}

The city region concept introduced a new way of thinking and planning, in terms of the Gauteng urban environment. The urban area is now characterized by multiple urban edges, all subject to the greater city region, and thus needs to function accordingly. The aim of the empirical investigation was to determine if it is more beneficial for the Gauteng city region to have only one urban development boundary and develop the entire area mono-centric, or whether it is more beneficial to maintain the current urban edges, and focus on a polycentric development pattern where all the urban nodes are interlinked, but function as individual entities. The empirical study consisted of three qualitative surveys conducted in the Metro-, the District-, and Local Municipalities, based on their location within the Gauteng city region.

The first survey covered the perceptions of the urban development boundary, the function and issues, the failures and success in order to develop an edge management decision support model for implementation and management. The second survey determined the sustainable development perspective in terms of strengths, weaknesses, opportunities and threats, in order to determine the development direction. The third survey determined the future development perspective in terms of polycentric approaches versus mono-centric approaches. 


\subsection{Conclusions drawn from the surveys}

The urban edge, in comparison with the urban development boundary concept, is a very one-dimensional approach. When planning a city region the focus needs to be wider and the approach more integrated and holistic. It is no longer only one guiding urban edge, but various interrelated urban development boundaries that will structure the urban environment. This polycentric approach testifies of a more homogenous development pattern, enhancing the economic perspective by distributing the economic sector, enhancing the environmental perspective by creating open green areas between urban nodes, and enhancing the social perspective by minimizing travel distances and introducing better social structures in all of the urban nodes. The polycentric development pattern thus reflects the objectives of sustainable development and therefore this pattern was identified as the way forward for Gauteng city region.

\section{Implementation}

The implementation of the urban development boundary concept would thus also introduce the polycentric development pattern in the Gauteng environment. Table 2 describes the impact evaluated in terms of economic delivery.

Table 2: $\quad$ Impact of the urban development boundary.

\begin{tabular}{|l|l|}
\hline & $\begin{array}{l}\text { Economic activity is the highest in the core. Polycentric development } \\
\text { increases the number of urban nodes, and the homogenous } \\
\text { development will ensure a smaller decline in the economic activity. }\end{array}$ \\
\hline
\end{tabular}

Source: Own construction.

Implementation of these concepts is subject to the current urban sprawl patterns and the ability to create alternatives for the development direction and guidance of the spatial plan. The success of the implementation is subject to growth management measures and good governance. The polycentric pattern recognizes the need for the broader urban development boundary (containing the entire Gauteng city region), as well as the need and functionality of smaller urban edges (of identified urban nodes), to control and manage the urban environment. This approach will ensure homogenous and integrated development. The urban development boundary will have a more definite role to play in terms of containing the economic forces, the social forces and the environmental forces, as well as structuring the polycentric development pattern. 
The theoretical concepts and proposed urban structures were accordingly implemented into the current reality of the Gauteng city region. Maps were created to illustrate the practical implementation, realization and obstacles that will be encountered in terms of the following issues:

Economic impacts: Gauteng shows a significant degree of spatial separation of poverty concentrations from economic activity. These areas were identified as economic nodes in need of infrastructure and support of economic status. These nodes are located on the outer parts of the current high growth economic areas, introducing economic growth nodes in declining areas.

Environmental impacts: Areas of natural and cultural significance are not only important from conservation and a quality of living point of view, but can also be regarded as important regional amenities. The identified environmental nodes were subject to conservation, ecological and cultural perspectives.

Social impacts: The suitability profile included the views and perspectives in terms of desirable locations to live and work, safe urban areas, and urban environments providing entertainment and social elements.

Transportation impacts: Transportation nodes were identified based on the central business areas, main destinations points and nodes formed around these zones. The origin of the flow is not as important as flow direction and impact.

The economic, environmental, social and transport nodes as identified structured the proposed polycentric development pattern for the Gauteng city region. This resulted in multi urban edges contained within the Gauteng urban environment. The urban development boundary will however guide and direct the spatial planning and manifestation of these nodes, as the urban development boundary is used as the tool to implement the polycentric development pattern, and therefore create a sustainable urban form by enhancing homogenous development, spatial equity, qualitative nodes, individual nodes and effective nodes.

\section{Management of the polycentric development pattern}

The success of the polycentric development pattern is subject to good management. To enhance the management, it is proposed that management should take place on two levels as illustrated in Figure 1. Firstly the provincial management level by managing the broader urban development boundary concept for the entire Gauteng city region. Secondly, the node management level by managing the individual urban edges of the identified urban nodes, to enhance functionality and compactness within the greater provincial polycentric concept.

The provincial management will control the urban development boundary in order to ensure the development of a sustainable urban form in the Gauteng city region. This should be managed through one authorising committee, and it is proposed that the committee should consist of at least two professionals of the following active departments of the Gauteng province: Department Agriculture, Conservation and Environment, Department of Economic Development, Department of Social Development, Department of Public Transport, Roads and Works and Department of Local Government. 
The node management level will control the individual urban edges of the identified nodes, ensuring compact nodes, efficient functioning and structuring of the polycentric development pattern. A sophisticated level of integrated and coordinated planning remains still a long way off (Harrison [12]) but it is proposed that the urban edges of the identified nodes must be managed locally by the municipalities. These managing authorities already manifest as the Metropolitan and District Municipalities of the Gauteng Province. These municipal structures can be used but need a development policy that will guide polycentric development, in order to set clear and concise development and spatial planning objectives, for the individual nodes, but also to enhance the impact of the specific urban node in terms of the Gauteng city region.

The polycentric development pattern, initiated by the urban development boundary concept needs to be supported by policies, legislation and frameworks describing the surrounding zonings and land use management within the Gauteng city region.

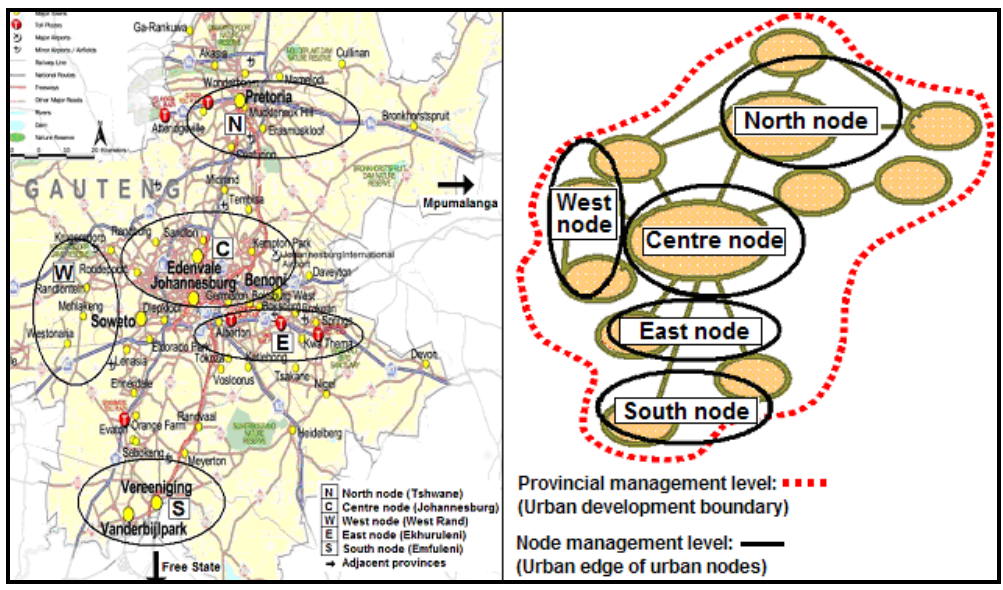

Figure 1: Levels of management.

\section{Tools for implementation of the polycentric pattern}

\subsection{Provincial management level}

The provincial management level focuses on managing the broader Gauteng urban development boundary. The managing authority needs an implementation tool that will ensure informed decision making when confronted with a specific development application. The proposed decision-making framework is based primarily on strategic decision-making and operational decision-making.

Strategic decision making is the first part of the decision-making process and focus on the organizing of activities through managerial control. Evaluation determines if the application will be approved, disapproved or suggested for amendment. The strategic decision-making framework is thus a simplified evaluation of a development application to determine if it is appropriate or 
inappropriate in terms of the environment in which it will be developed. If an application is found to be inappropriate, it is immediately disapproved. If this application is concluded to be appropriate in terms of the strategic decisionmaking, with reference to the greater environment and polycentric development pattern, it will proceed to the operational decision-making. Operational decisionmaking evaluates development potential on merit, as development potential is also influenced by the specific characteristics and impacts of the area. To this effect, an operational decision-making model is utilized, focusing on merit evaluations. The model is pragmatic and is based on the assignment of values to various specific location factors. The Provincial management level should at all times be times focused on the objectives of the broader urban development boundary, and identified rural areas should only be brought into the urban growth boundary, if it can accommodate future growth.

\subsection{Node management level}

The Node management level focuses on managing the individual urban edges of the identified nodes, to enhance functionality and compactness within the greater provincial concept. This is an integrated approach towards structuring the polycentric development pattern. The managing authorities need an implementation tool that will ensure informed decision making when confronted with a specific development application.

The proposed decision-making framework manifest as an evaluation tool, helping local authorities to determine if the application will be aligned with the current spatial planning and development objectives of the specific urban node and polycentric development pattern. It is used to compare the various costs, options and trade-offs in order to make more informed location decisions. The application is interpreted by the local authorities in terms of the policy and motivation. The evaluation is done in terms of environmental issues, cultural, historical and heritage issues, visual and place elements, as well as engineering issues. After the evaluation, a sensitivity analysis is done. This is based on the normative position in terms of location and the specific characteristic of the applicable site with regards to structuring elements, which will create uniqueness and promote sustainability. The edge management decision support model follows a simple checklist approach. It creates awareness about the questions that need to be asked and assessments that need to be done, before a decision is made in terms of development within the urban nodes. Evaluation of the application is done in terms of low, medium or high impact, and the result of the evaluation will guide the approving or disapproving of the application. The decision support model for the will thus manage the individual urban edges of the identified urban nodes. Table 3 is a summary of the proposed management and control measures.

\section{Conclusion}

Good governance is the key in terms of evaluation and monitoring. The urban development boundary should act as the container of the polycentric 
Table 3: $\quad$ Summary of the proposed management and control measures.

\begin{tabular}{|l|l|l|}
\hline Manage & Provincial management level & Node management level \\
\hline Goal & $\begin{array}{l}\text { Managing the urban development } \\
\text { boundary for the entire urban area }\end{array}$ & $\begin{array}{l}\text { Manage urban edges of individual } \\
\text { identified urban nodes }\end{array}$ \\
\hline Applicable & $\begin{array}{l}\text { Applications outside the current urban } \\
\text { edges of the identified nodes }\end{array}$ & $\begin{array}{l}\text { Inside the urban edges of the specific } \\
\text { identified urban nodes }\end{array}$ \\
\hline Focus & Gauteng city region & Enhance functionality/compactness \\
\hline Tool & Urban development boundary & Urban edges of urban nodes \\
\hline Objective & $\begin{array}{l}\text { Efficient and effective functioning } \\
\text { and structuring of polycentric pattern }\end{array}$ & $\begin{array}{l}\text { Containment of the identified urban } \\
\text { nodes, creating polycentric development } \\
\text { pattern }\end{array}$ \\
\hline Authority & One authorising committee & Metropolitan municipalities that \\
\hline Tools & $\begin{array}{l}\text { This decision-making framework is } \\
\text { based on strategic decision-making } \\
\text { and operational decision-making. }\end{array}$ & $\begin{array}{l}\text { Decision-making framework theck that } \\
\text { follows a checklist approach in terms of } \\
\text { low/medium/high impact. }\end{array}$ \\
\hline
\end{tabular}

Source: Own construction

Table 4: $\quad$ Comparison of the proposed development initiatives.

\begin{tabular}{|c|c|c|c|c|}
\hline & Element & $\begin{array}{c}\text { Current reality: } \\
\text { Gauteng city region }\end{array}$ & $\begin{array}{c}\text { Urban Boundary: } \\
\text { 'rovincial managemen }\end{array}$ & $\begin{array}{c}\text { Urban edge concept: } \\
\text { Node management }\end{array}$ \\
\hline \multirow{6}{*}{ 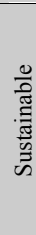 } & Environment & No protection measures & Green linkages & Enhance open areas \\
\hline & Open spaces & Green areas non existent & Planning of open spaces & $\begin{array}{c}\text { Transition (urban vs. } \\
\text { rural) }\end{array}$ \\
\hline & Transport & Ignores boundaries & Planned network for area & Network link urban nodes \\
\hline & Economy & $\begin{array}{c}\text { Core urban areas move } \\
\text { to the periphery }\end{array}$ & $\begin{array}{l}\text { Restrict development } \\
\text { outside the boundary }\end{array}$ & $\begin{array}{l}\text { Contain urban core and } \\
\text { thus economic core }\end{array}$ \\
\hline & Social & No social component & Develop social zones & Contain urban/social core \\
\hline & Success & Not sustainable & Yes, develop holistically & Integrating spheres \\
\hline \multirow{4}{*}{ 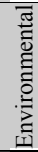 } & Management & No statuary value & Sustainable spatial act & Urban edge policies \& tools \\
\hline & Objective & $\begin{array}{c}\text { Development in stead of } \\
\text { conservation }\end{array}$ & $\begin{array}{l}\text { No development in } \\
\text { environmental areas }\end{array}$ & $\begin{array}{l}\text { Limited development in } \\
\text { environmental areas }\end{array}$ \\
\hline & SEA, EMP (Policies) & Not effective & Integrated into act & Requirement \\
\hline & Success & No management & Yes, Provincial level & Yes, Node management \\
\hline \multirow{7}{*}{ 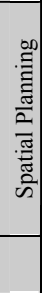 } & $\begin{array}{c}\text { Land use } \\
\text { management }\end{array}$ & Not effectively & Requirement & Inside edge applicable \\
\hline & Development & Not controlled. Sprawl & Polycentric development & Controlled inside edge \\
\hline & Regulations & Town Planning Schemes & $\begin{array}{l}\text { Acts. Decision-making } \\
\text { tools }\end{array}$ & Policies and tools \\
\hline & Degrading of core & High & Low & Low \\
\hline & Nodes & Unplanned disparity & Polycentric development & Urban nodes with edge \\
\hline & Success & Unsuccessful & Yes, holistic approach & Yes, integrated \\
\hline & Element & $\begin{array}{c}\text { Current reality: } \\
\text { Gauteng city region }\end{array}$ & $\begin{array}{c}\text { Urban Boundary: } \\
\text { 'rovincial managemen }\end{array}$ & $\begin{array}{l}\text { Urban edge concept: } \\
\text { Node management }\end{array}$ \\
\hline \multirow{4}{*}{$\begin{array}{l}\overrightarrow{0} \\
\text { ह } \\
\text { | } \\
0 \\
0 \\
0\end{array}$} & Structure & $\begin{array}{c}\text { Local, District, Metro } \\
\text { Municipality }\end{array}$ & $\begin{array}{l}\text { Gauteng Department of } \\
\text { Development Planning }\end{array}$ & $\begin{array}{l}\text { District and Metropolitan } \\
\text { municipalities }\end{array}$ \\
\hline & Roles & Not clear & Development control & Development management \\
\hline & Responsibility & Economic hub & Guide pole development & Enhance node function \\
\hline & Success & Inefficient & Effective provincial level & Effective Local level \\
\hline \multirow{6}{*}{ 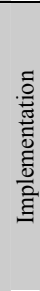 } & Authority & Municipal manager & $\begin{array}{l}\text { Gauteng Department of } \\
\text { Development Planning }\end{array}$ & $\begin{array}{c}\text { District \& Metropolitan } \\
\text { municipalities }\end{array}$ \\
\hline & Development & Uncontrolled & Guide urban form & Ensure compaction \\
\hline & Monitoring & No & $\begin{array}{c}\text { Decision-making } \\
\text { frameworks }\end{array}$ & $\begin{array}{c}\text { Decision-making } \\
\text { frameworks }\end{array}$ \\
\hline & $\begin{array}{l}\text { Development } \\
\text { response }\end{array}$ & Urban sprawl & Create new node & Increase densities \\
\hline & Effectiveness & $\begin{array}{c}\text { Not implemented } \\
\text { optimal }\end{array}$ & High & High \\
\hline & Containment & Limited & Metropolitan & Urban nodes \\
\hline
\end{tabular}


development pattern, regulating urban development in the Gauteng city region. It is concluded that the planning tool, the urban development boundary, can be used by the relevant role players to guide development towards a sustainable urban form. The urban development boundary initiates applicable development patterns of polycentric development and urban node containment. Table 4 illustrates, in conclusion, the comparison of the current phenomenon in Gauteng, the urban development boundary concept (as proposed for the provincial management level), and the urban edge concept (as proposed for the node management level). The future of our world will be the outcome of what we, the urban people, do about it, through our projects and conflicts (Evens [13]).

\section{References}

[1] Dewar, D. Urbanization and the South African city: A Manifesto for Change. University of Cape Town, Urban Problems research Unit. Cape Town. 1992.

[2] Schoeman, C.B. The Interface between Environmental Management, Spatial Planning and Land Use Management from a Development Perspective. Pretoria. 39p. 2006.

[3] Steyn, P. Environmental Management in South Africa: twenty years of governmental response to the global challenge. 1972-1992. Historia 46(1). p25-53.) 2001.

[4] Sowman, M \& Gawith, M. Participation of disadvantaged communities in project planning and decision-making: A case study of Houtbay. Development Southern Africa. 11(4), p557-571. 1994.

[5] Republic of South Africa: Subdivision of Agricultural Land Act. (Act 70 of 1970): Government Printer, Pretoria. 1970.

[6] Republic of South Africa: Department of Provincial and Local Government. Municipal Planning and Performance Management Regulations (No. R 796). Government Printer, Pretoria. 2001.

[7] Western Cape Department of Environmental Affairs and Development Planning. Provincial Guideline on Biodiversity Offsets. Cape Town. 2006.

[8] Ekhuruleni Metropolitan Municipality (South Africa). Drafting of master set of land use management scheme clauses. Setplan development. 2006.

[9] Gauteng Provincial Government. (South Africa). Gauteng Spatial Development Framework. Prepared for Gauteng Department of Economic Development. Pretoria. 2006.

[10] Metro Dade. The Urban Development Boundary: Holding the Line for our quality of life. Pretoria.2008.

[11] Gauteng Department of Economic Development. Revision of the Gauteng Urban development boundary. Draft Report. 2006.

[12] Harrison, P. The Genealogy of South Africa's Integrated Development Plan. Third World Planning Review. 23(2). 2001.

[13] Evens, P. Liveable cities: Urban struggles for livelihood and sustainability. University of California Press. 277p, 2001. 